\title{
Linear Knife Grid Application for Biomass Size Reduction
}

\section{Igathinathane, Ph.D.}

2506 E.J. Chapman Drive, Department of Biosystems Engineering and Soil Science, The University of Tennessee, Knoxville, TN 37996-4531, igathi@utk.edu

Alvin R. Womac, Ph.D., P.E.

2506 E.J. Chapman Drive, Dept. of Biosystems Engg. and Soil Sci., The University of

Tennessee, Knoxville, TN 37996-4531, awomac@utk.edu

\section{Petre I. Miu, Ph.D., P.Eng.}

2506 E.J. Chapman Drive, Dept. of Biosystems Engg. and Soil Sci., The University of Tennessee, Knoxville, TN 37996-4531, pmiu@utk.edu

\section{Manlu Yu, MS}

2506 E.J. Chapman Drive, Dept. of Biosystems Engg. and Soil Sci., The University of Tennessee, Knoxville, TN 37996-4531, myu@utk.edu

\section{Shahab Sokhansanj, Ph.D., P.E.}

Oak Ridge National Laboratory, Environmental Sciences Division, P.O. Box 2008, Oak Ridge TN 37831-6422, sokhansanjs@ornl.gov

\section{Sundar Narayan, Ph.D.}

First American Scientific Company, 100 Park Royal South West Vancouver, British Columbia Canada, V7T 1A2, sundar@fasc.net

\author{
Written for presentation at the \\ 2006 ASABE Annual International Meeting$$
\text { Sponsored by ASABE }
$$$$
\text { Portland Convention Center }
$$$$
\text { Portland, Oregon }
$$$$
9 \text { - } 12 \text { July } 2006
$$

\footnotetext{
The authors are solely responsible for the content of this technical presentation. The technical presentation does not necessarily reflect the official position of the American Society of Agricultural and Biological Engineers (ASABE), and its printing and distribution does not constitute an endorsement of views which may be expressed. Technical presentations are not subject to the formal peer review process by ASABE editorial committees; therefore, they are not to be presented as refereed publications. Citation of this work should state that it is from an ASABE meeting paper. EXAMPLE: Author's Last Name, Initials. 2006. Title of Presentation. ASABE Paper No. 06xxxx. St. Joseph, Mich.: ASABE. For information about securing permission to reprint or reproduce a technical presentation, please contact ASABE at rutter@asabe.org or 269-429-0300 (2950 Niles Road, St. Joseph, MI 49085-9659 USA).
} 


\begin{abstract}
Most of the commonly used biomass size reduction devices use rotary action. An alternative mode of size reduction is by linear action of cutting element directly on the biomass material. A linear action knife grid model device was developed to as a prototype to solve issues related to scale-up and determine cutting characteristics of selected biomass materials. Major components of the prototype were ram, feed block, knife grid, knife holder block, product block, and bottom tray. Tool steel hardened knifes were arranged in a square grid pattern and their spacing was adjustable. The whole assembly were mounted and tested on a universal testing machine. Dry corn stalks and switchgrass were selected as the test materials. Cutting experiments were conducted at various grid spacing, fill depths, and refill runs. The output variables measured were maximum force, peak stress, energy, material mat thickness, and mass of products after each refill runs. New surface generated by the cuts will be evaluated theoretically using the circle packing theory. Ultimate cutting stress and net energy requirements increased with increasing fill depth and decreasing knife grid spacing. A final product size of $50 \mathrm{~mm}$ required $1.69 \pm 0.81 \mathrm{kWh} / \mathrm{t}$ for corn stalks and $0.49 \pm 0.04$ for switchgrass, while a product size of $101 \mathrm{~mm}$ required $0.48 \pm 0.08 \mathrm{kWh} / \mathrm{t}$ for corn stalks and $0.14 \pm 0.02$ $\mathrm{kWh} / \mathrm{t}$ for switchgrass. Mean values of specific energy based on new surface generated were estimated as $83.78 \pm 24.5$ and $63.34 \pm 12.3 \mathrm{kN} / \mathrm{m}$ for corn stalks and $21.50 \pm 1.9$ and $15.53 \pm 1.7 \mathrm{kN} / \mathrm{m}$ for switchgrass for product size of 50 and $101 \mathrm{~mm}$, respectively. Corn stalks required 3.3 to 3.4 , and 3.9 to 4.1 times higher cutting energy than switchgrass based on mass and new surface area generated energy basis, respectively. Scaling up is highly feasible for large product sizes because the determined specific energy values are small; and they are well below the reported values.
\end{abstract}

Keywords. Biomass, Cutting, Device, Energy requirements, Knife, Size reduction, Stress 


\section{Introduction}

Biomass size reduction is an essential preprocessing step in the overall bioproducts processing. Most commonly used biomass size reduction machines are hammer mill, chopper, chipper, shredder, and disc mill. These grinders have a rotary action. An alternative mode of size reduction is by linear action of cutting element directly on the biomass material. It is of interest to determine the variation in the energy requirement versus rotary grinders.

Research work on energy requirement of cutting operation of fibrous materials was limited (Brennan, et al. 1990). Dowgiallo (2005) reported that there is neither a cutting theory nor a mathematical formula for cutting resistance for fibrous materials. He developed a theoretical model for cutting force based on knife cutting speed, material, and knife parameters. He found that the unit power of cutting fibrous material with a knife of defined geometry (thickness and blade angle) is a constant value. Some of the studies on cutting energy requirements on fibrous materials like soybean stalks (Mesquita and Hanna, 1995), cotton stalks (El Hag et al., 1971), maize stalks (Prasad and Gupta, 1975), alfalfa stems (Prince et al., 1969), and hemp (Chen et al., 2004). These studies showed that cutting energy is related to the stem mechanical properties (e.g. maximum cutting force and stem shear strength), and physical properties (e.g. stem diameter, dry matter density and moisture content). Type of cutting knife and blade edge also affect the cutting energy requirement. A serrated blade edge gives a higher cutting force and requires more cutting energy than a smooth edge (Persson, 1987). O'Dogherty (1982) reviewed the forage chopping research and Yu et al. (2003) reviewed biomass size reduction technologies.

Linear cutting actions of blades on biomass material against a bearing surface tend to be different from the rotary action of cutting element of the rotary size reduction machines, owing to the presentation of materials to the path of blade movement. Such linear action can either be applied with or without impact. Some compression of the bulky fibrous biomass material occurs before actual cutting, especially when the linear action is performed without impact.

Objectives of the present study were:

- To develop a linear knife grid model as a prototype to solve issues related to scale-up.

- To test the knife grid model using universal testing machine (UTM) to determine maximum failure load, ultimate cutting stress, and energy involved in cutting corn stalks and switchgrass and the effect of knife grid spacing.

\section{Materials and Methods}

\section{Description and Specification of Linear Knife Grid Model Cutting Device}

The components and their functions linear knife grid model cutting device were 1. Ram block attached to UTM cross head and provides the cutting load, 2. Feed block - holds the biomass material during cutting, 3. Knife grid - cross lap joints of bottom and top knives produce square grid arrangement of knife edges, and specific sets of top and bottom knives made the required knife grid spacing, 4. Knife support block - grooves spaced at $25.4 \mathrm{~mm}$ interval holds the knives in position at required spacing during cutting, 5. Product block - support the bottom set of knives and collects the cut product, 6 . Bottom holder - holds all the above components and attached to UTM bed (Fig. 1). All the components, as applicable, will have ridge on the top and corresponding step on the bottom side so that they all were assembled one over the other in a 
proper order. With some types of UTM, the bottom tray will be eliminated from the components assembly, as the feed block can be directly rested on the bed of UTM.

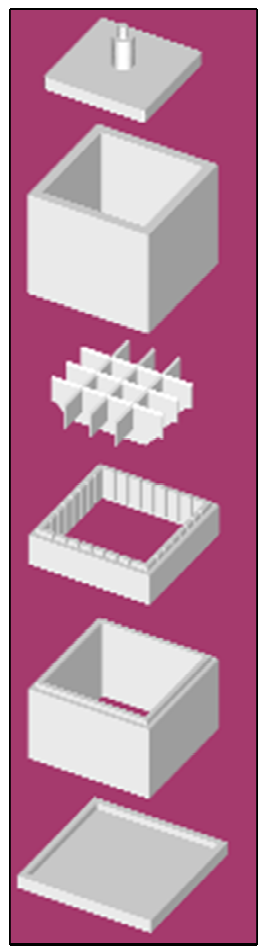

Ram
Feed block (8" square)

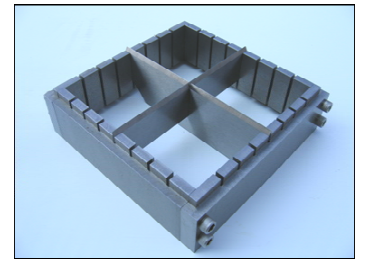

Knife grid

(4" spacing)

Knife grid

Knlfe support block

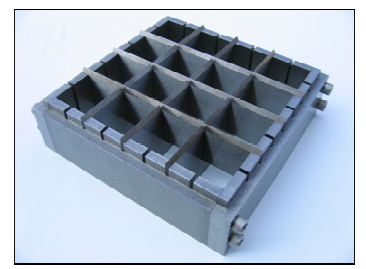

Knife grid

(2" spacing)

Product block

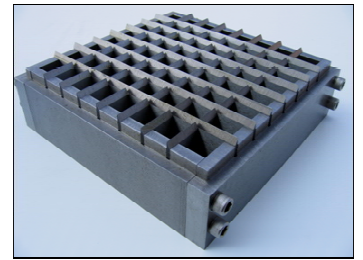

Knife grid

(1" spacing)

Figure 1. Components of linear knife grid model cutting device and knives arrangement at various grid spacing.

All blocks have an inner dimension of $203.2 \mathrm{~mm}\left(8^{\prime \prime}\right)$ and were made from $19.05 \mathrm{~mm}\left(0.75^{\prime \prime}\right)$ mild steel plates, and are connected by $9.53 \mathrm{~mm} \mathrm{(3/8")} \mathrm{UNC} \mathrm{grade} 8$ bolts. Clearance of 0.16 $\mathrm{mm}(1 / 160 ")$ was provided between ram and feed block. Mating parts, such as the component blocks, and knifes and slots of knife holder block were provided a running fit. Knife material was tool-steel A2 and for other parts mild steel was used. Knives were sharpened and machined by laser processes and were heat treated. Knives were $3.18 \mathrm{~mm}\left(1 / 8^{\prime \prime}\right)$ thick plates and were given single bevel with angle of $30^{\circ}$.

\section{Biomass selection and sample preparation}

Dry corn stover and switchgrass, obtained from the Experiment Research Station, The University of Tennessee, Knoxville, were selected as test material. Stalks were prioritized for testing in the case of corn stover as they form the major component contributing about $72.57 \%$ wet mass of corn stover (Igathinathane et al., 2006).

Test samples were prepared by removing the leaves, cobs, and husk. Prepared stalks were initially cut to lengths a little less than $20.3 \mathrm{~mm}\left(8^{\prime \prime}\right)$, so that they were freely loaded into the feed block. Mats of switchgrass from the rectangular bales were cut to approximately $20 \mathrm{~mm}$ long, and the separated loose stems with leaves were loaded into the feed block.

The moisture content of the samples was evaluated using the ASAE Standard S358.2 (ASAE Standards, 2003). 


\section{UTM Description and Setting}

Mechanical cutting tests were performed in a UTM (Measurement Technology, Inc. Roswell, GA; Product: MTI Phoenix; Model No: 60 K) fitted with 22680 kg (50000 lb) load cell (Fig. 2). The accompanied software MTI Universal Testing System 32 bit Testing Application Programs, Ver. 1.15, 1997 operated the machine and recorded the results. Data acquisition sampling rate was in the range of 50 to 75 cycles/min. Outputs stored in text format can be further analyzed using appropriate packages. Since this UTM had a plane bed, the product block was directly set on the bed with out bottom tray.

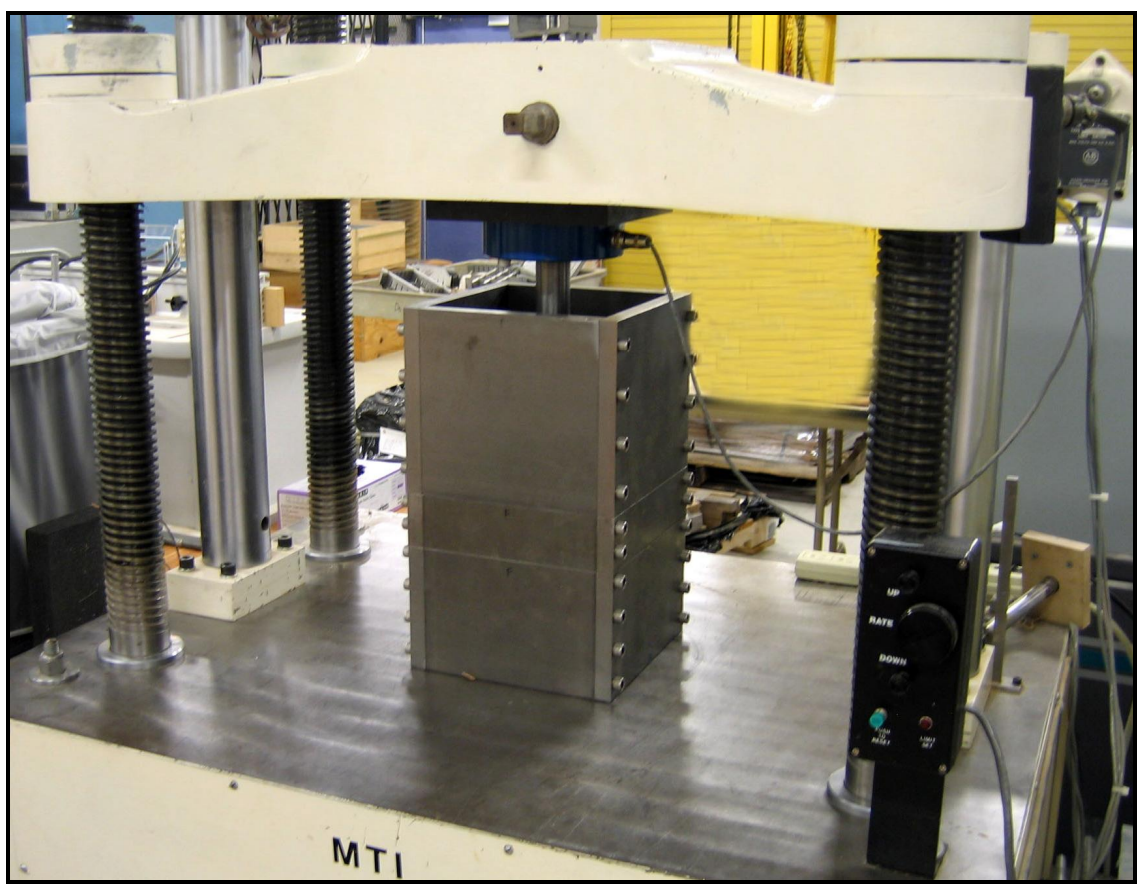

Figure 2. Universal testing machine (MTI; Capacity $22680 \mathrm{~kg}$ ) with assembled linear knife grid model cutting device being tested.

During all experiments a maximum available speed of $50.8 \mathrm{~mm} / \mathrm{min}(2 \mathrm{in} / \mathrm{min})$ was used. An upper load limit of $13608 \mathrm{~kg}(30000 \mathrm{lb})$ in most cases, though a $18144 \mathrm{~kg}(40000 \mathrm{lb})$ in special circumstances were considered. To allow a clearance of $3.18 \mathrm{~mm}(1 / 8$ ") between the ram bottom and the horizontal plane of the cutting edges of knife grid, the ram movement was restricted to fixed distance of $176.21 \mathrm{~mm}\left(615 / 16^{\prime \prime}\right)$ after aligning the top surfaces of the ram and the feed block. Aligning of the ram and feed block surfaces can be visually checked. Straight downward movement of the ram block also had a self-aligning action on the whole assembly of linear knife grid device components. Inner walls of the feed block were marked at $50.8,101.6$, and $152.4 \mathrm{~mm}\left(2^{\prime \prime}, 4 "\right.$, and 6") levels measured from the plane of knife edges, to aid in sample filling to specified depths.

\section{Test Procedure}

Prepared test materials were filled in the feed block to the required depths previously marked. The mass of material filled to specified depth was assessed from the masses of the excess sample measured before filling and that remaining after filling. Any material fell through the knife grid spacing can be removed by carefully sliding the entire assembly and reaching from the bottom. 
After positioning the assembly, the ram was moved slowly by manual control of crosshead to ensure proper entry of ram into the feed block. Manual operation was continued until the top surfaces of ram and feed block were at same level. Then the test was carried out using the computer software with the preset limits already mentioned until the finish. In most cases, the crosshead displacement limit signaled the end point of test. The crosshead was then moved up at the same rate using the "unload" command. This unloading took the ram to the original position with its top surface aligned with the feed block top surface, therefore the ram should be further lifted to release the feed block for taking out the products.

Thickness of the compressed mat of the sample was measured by measuring the levels from the feed block top surface. Mass of cut product produced was determined after collecting them by sliding the whole assembly partially out of the bed. Without disturbing the compressed mat, the subsequent fillings were made and the procedure was repeated for four to five times. After the final run, the feed block was taken off and the tested sample was manually separated as different categories such as, wholes only compressed, wholes but partially cut, partial cut product, cut product caught in grid, and their masses were determined.

\section{Experimental Variables}

The independent variables were:
Crop:
Corn stover and switchgrass
Knife grid spacing:
$25.4 \mathrm{~mm}, 50.8 \mathrm{~mm}, 101.6 \mathrm{~mm}$; on square grid
Sample depth:
$50.8 \mathrm{~mm}, 101.6 \mathrm{~mm}$, and $152.4 \mathrm{~mm}$
Number of refills:
4 or 5 .

The output variables measured were maximum force, peak stress, energy, mat thickness, mass of products after each refill runs, and mass of different fractions at the end of experiments.

\section{Data Analysis}

Ultimate cutting stress was evaluated based on the peak load divided by the fixed cross sectional area of the feed block $(203.2 \mathrm{~mm} \times 203.2 \mathrm{~mm})$. It should be noted that the area used for these stress calculations was the fixed area of cross section of the feed block and not the actual area of cut surfaces, which cannot be readily measured. However, this method was valid for the compression tests carried out. Nevertheless, a rigorous ultimate cutting stress calculation should consider the actual cut area generated. But this simpler method of ultimate cutting stress calculation provides an idea about the variation trends.

Energy values produced by the software were the total energy based on the entire loaddisplacement characteristics that included the initial ram idle run. Net cutting energy, represented only by the area under the load-displacement characteristics during which the actual compression and cutting happened, was obtained from the data integration after eliminating the initial ram idle run as well as subtracting the energy involved during withdrawal of ram.

Specific energy involved in the cutting operation can be expressed in mass and new surface area generated basis. Specific energy based on mass was presented on the basis of the masses of input material used and product produced. The new surface generated by the length of the blade cutting through the material filled to a specified depth was calculated theoretically based on circle packing theory. 
Assuming a cylinder geometry for corn stalks and switchgrass with a length ' $"$ ' and cross sectional diameter ' $d$ ', the number of cylinders ' $n$ ' that can be packed on an area of dimension ' $L$ ' and ' $D$ ' with cylinder axis perpendicular to the area in a straight matrix arrangement will be $n=(L / d) \times(D / d)$. Therefore the total cross sectional area ' $s$ ' of all the packed cylinders will be product of ' $n$ ' and cross sectional area of cylinder. This number will increase when the ' $d$ ' had a distribution of values, which is the case with all actual samples. Packing density ' $\sigma$ ', defined as the ratio of the total area occupied by the packed material and the area available for packing $(L \times D)$, of the material was calculated from the assumed ' $d$ ' values of the samples. With the packing density the area occupied by the cylinders available for packing can be easily obtained as $s=\sigma \times L \times D$. The total new surface generated by the knife grid will be the product of the number of knifes and the area (s) occupied by the packed cylinder in a single cutting plane.

\section{Results and Discussion}

\section{Typical Load-Displacement Characteristics Curves}

\section{Compression characteristics}

It is well understood that the fibrous biomass material should undergo compression before actual cutting starts (Chancellor, 1958). Figure 3 shows the load-displacement characteristics of corn stalks and switchgrass with complete fill of $152.4 \mathrm{~mm}$.

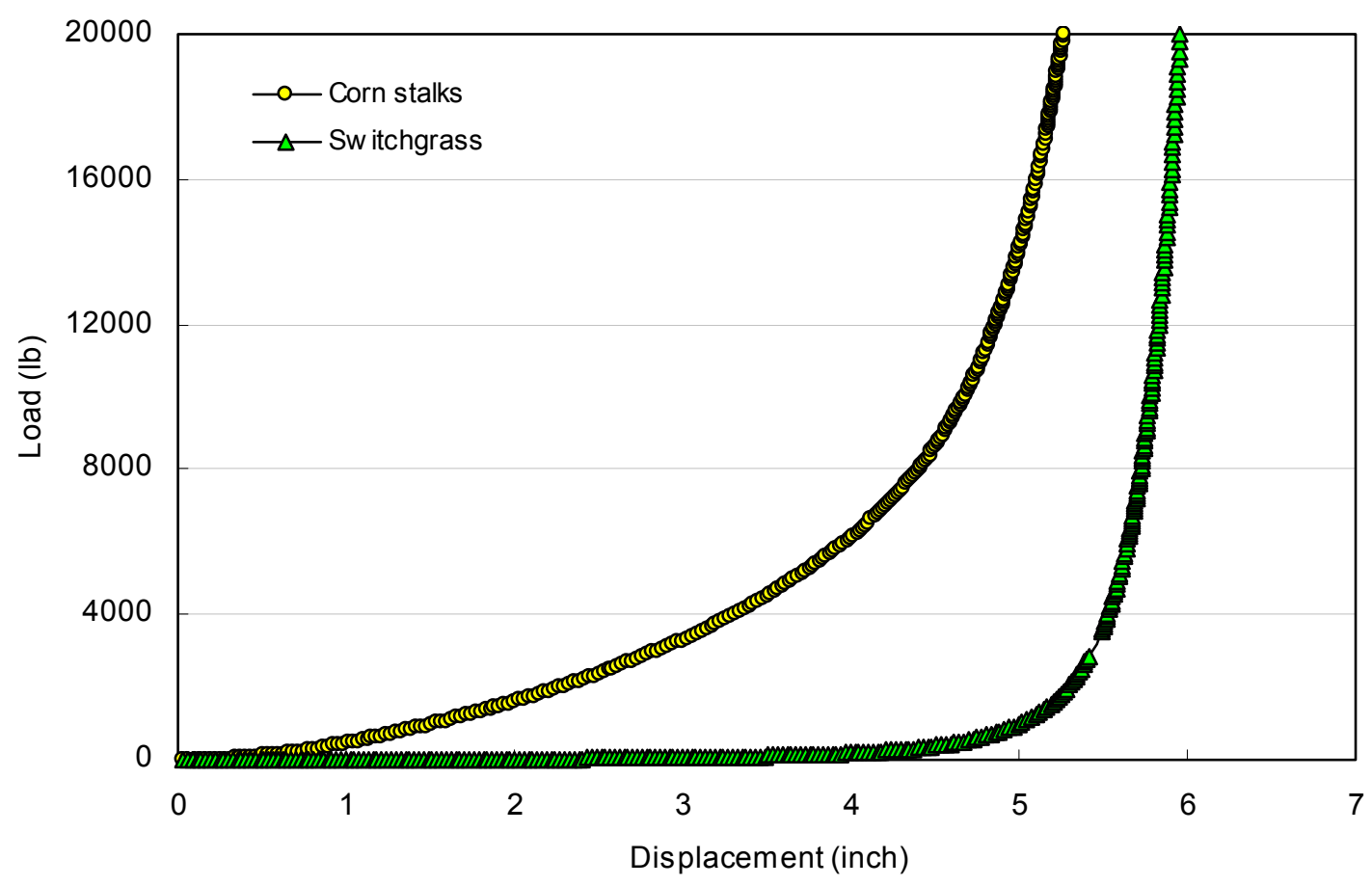

Figure 3. Simple compression characteristics of corn stalks and switchgrass with 6 inch fill.

Corn stalks displayed a gradual increase of load with compressive deformation during the initial stages and a sharp increase at a later stage signifying the densification and consolidation. Switchgrass on the other hand showed no increase of load until $114 \mathrm{~mm}$ deformation, which essentially means air expulsion from the load input sample material, and once a mat of the material was formed it offered more resistance to further deformation than corn stalks in a 
similar situation. The steep increase of load, almost vertical after a $140 \mathrm{~mm}$ displacement, proves the incompressible nature of switchgrass. Hence, it was evident that a huge amount of force was required to compress the material before initiating the cutting process. Also with similar filling and loading conditions, cutting of corn stalks will happen earlier while the switchgrass was still under compression.

\section{Cutting characteristics of corn stover}

Corn stover cutting characteristics of the second refill run under linear knife grid at two knife grid spacing are plotted in Figure 4. Initial mat formation of the material was already completed during the first run. When the knife grid spacing was smaller, the load-displacement characteristics at $50.8 \mathrm{~mm} \mathrm{(2")} \mathrm{spacing} \mathrm{were} \mathrm{similar} \mathrm{to} \mathrm{that} \mathrm{of} \mathrm{simple} \mathrm{compression} \mathrm{(Fig.} \mathrm{3),} \mathrm{and}$ signs of major cutting activity were not seen from the curve. When the grid spacing was doubled from 50.8 to $101.6 \mathrm{~mm}(2$ " to $4 ")$, the peak force was reduced by $\sim 6.7$ times. This observation leads to the conclusion that smaller the grid size, which governs the product size, the larger the force required to cut. With wider spacing of $101.6 \mathrm{~mm}$, the cutting characteristics showed several peaks signifying the cutting actions. Reduction of loads after peak illustrated the failure of material structure and formation of failure planes that offered a reduced resistance to the relative movement of the blades. The peaks may also be attributed to the gap between the compressed corn stalks. A clear overall peak was seen from the characteristics, which corresponded to the maximum cutting force required.

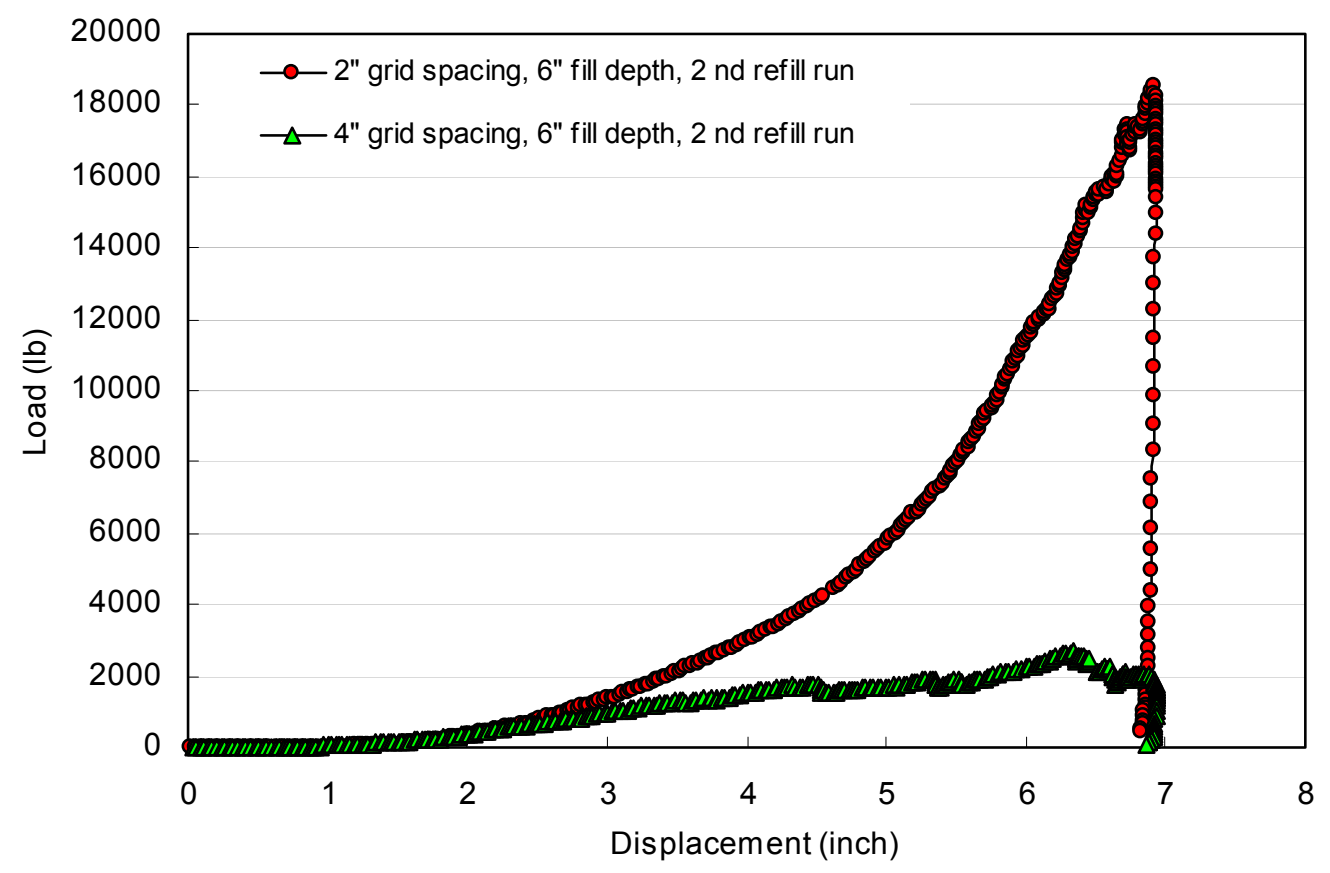

Figure 4. Typical load-displacement cutting characteristics of corn stalks under linear knife grid.

\section{Cutting characteristics of switchgrass}

Figure 5 shows the switchgrass cutting characteristics under knife grid at two different knife grid spacing. 


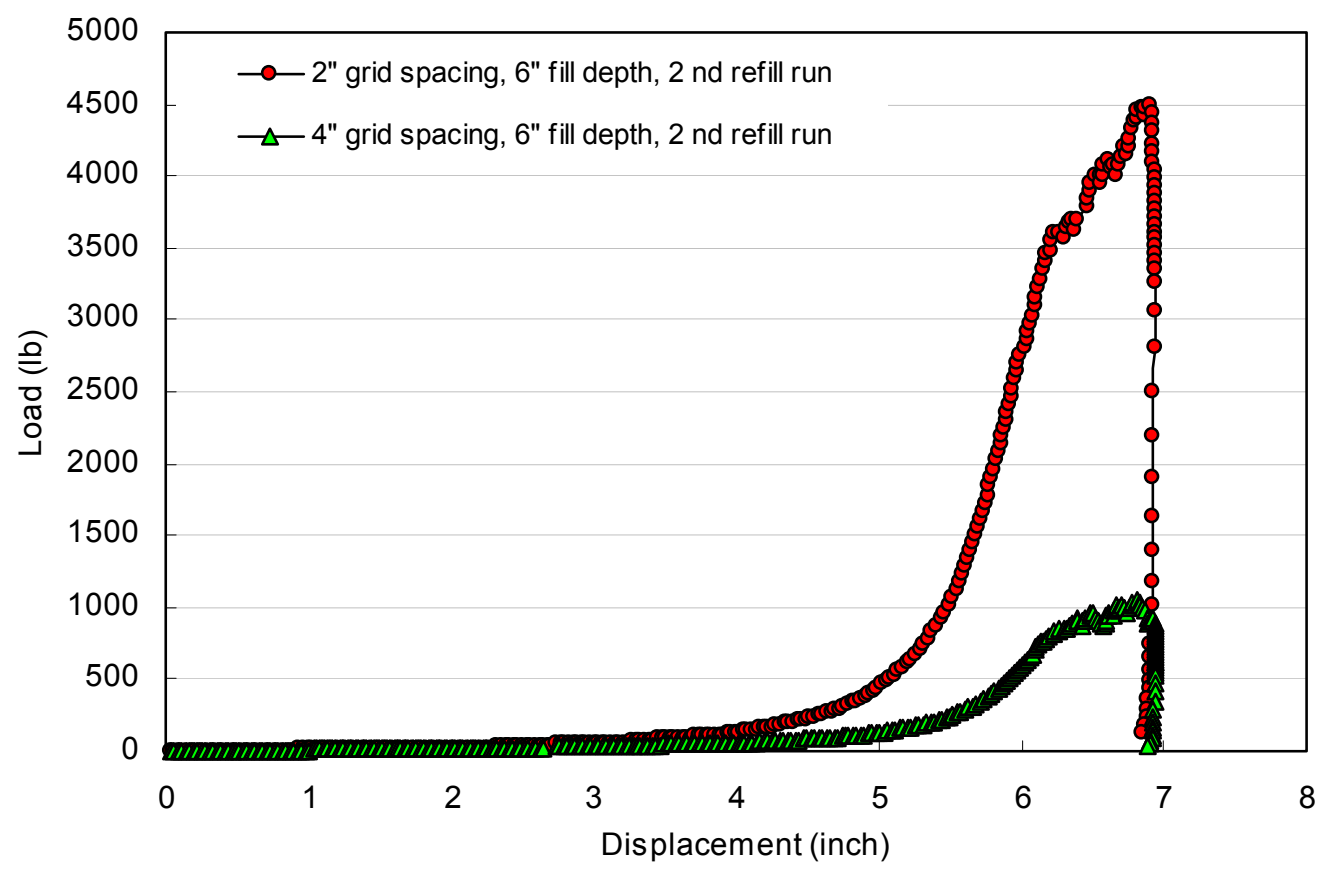

Figure 5. Typical load-displacement cutting characteristics of switchgrass under linear knife grid.

As observed in pure compression characteristics (Fig. 4), most of the deformation did the consolidation; but the cutting activity, depicted by the peaks, happened one during the end of the run. Doubling the knife grid spacing reduced the peak force by $\sim 4.7$ times. Again with switchgrass, closer spacing followed the compression characteristics and showed an overall increasing trend, but the wider spacing produced more cutting activities at a relatively constant load. The return leg of the curves (Fig. 4 and 5) corresponds to the unloading force recorded during the ram withdrawal. This unloading produced a negative area under the loaddisplacement curve, and the associated energy was subtracted to obtain the net energy.

Another resistive force to be accounted was the one that corresponds to the pushing of cut products though the grid. This force can be thought of that involved in an extrusion process, since the area of openings above the knife grid was greater than that below the grid because of the thickness of the knife elements, and the product was squeezed through the grid before reaching the product block. Though the knife edges were sharp and their thicknesses were negligible, the knife element body has a thickness of $3.18 \mathrm{~mm}\left(1 / 8^{\prime \prime}\right)$, which was required to meet the mechanical strength requirements. The squeezing effect, in combination with the inclined bevel edge of knife, makes the product to twist and get embedded in the annular space of the knife grid (Fig. 6). 

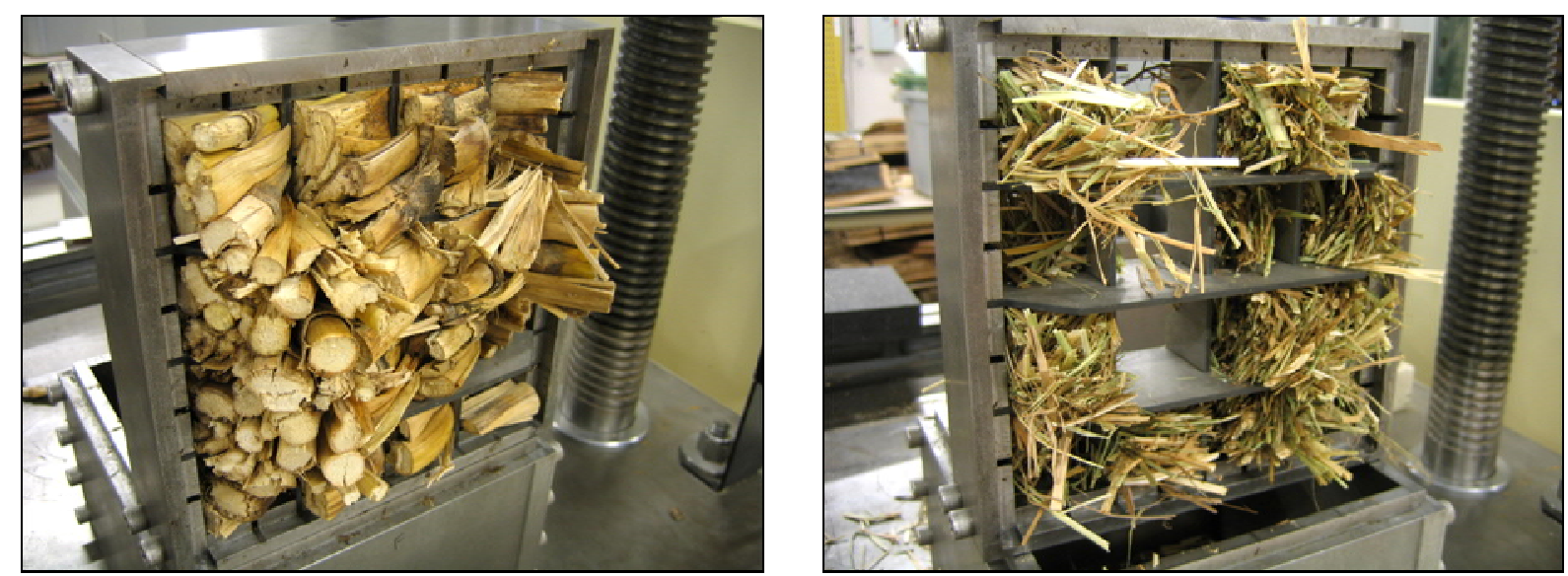

Figure 6. Cut product embedded in the knife grid annular space (50.8 mm (2") knife grid spacing).

This extrusion phenomenon consumed some portion of the useful cutting force and it increased with reduction in knife grid spacing.

In a trial run with $25.4 \mathrm{~mm}(1 ")$ knife grid spacing, the UTM capacity was exceeded when the ram was at an intermittent stage during the run. Due to a significant load requirement, the experiments with $25.4 \mathrm{~mm}$ spacing were interrupted.

\section{Cutting Stress}

Cutting stress in cutting of corn stalks and switchgrass based on knife grid spacing and depth of filling in relation to the number of refills are shown in Figure 7. It is logical to use the active area perpendicular to the ram as most of the cutting characteristics (Figs. 4 and 5) were similar to compression characteristics curves (Fig. 3). Ultimate stresses were smaller at larger grid spacing as well as at reduced fill depths, and vice-versa. 

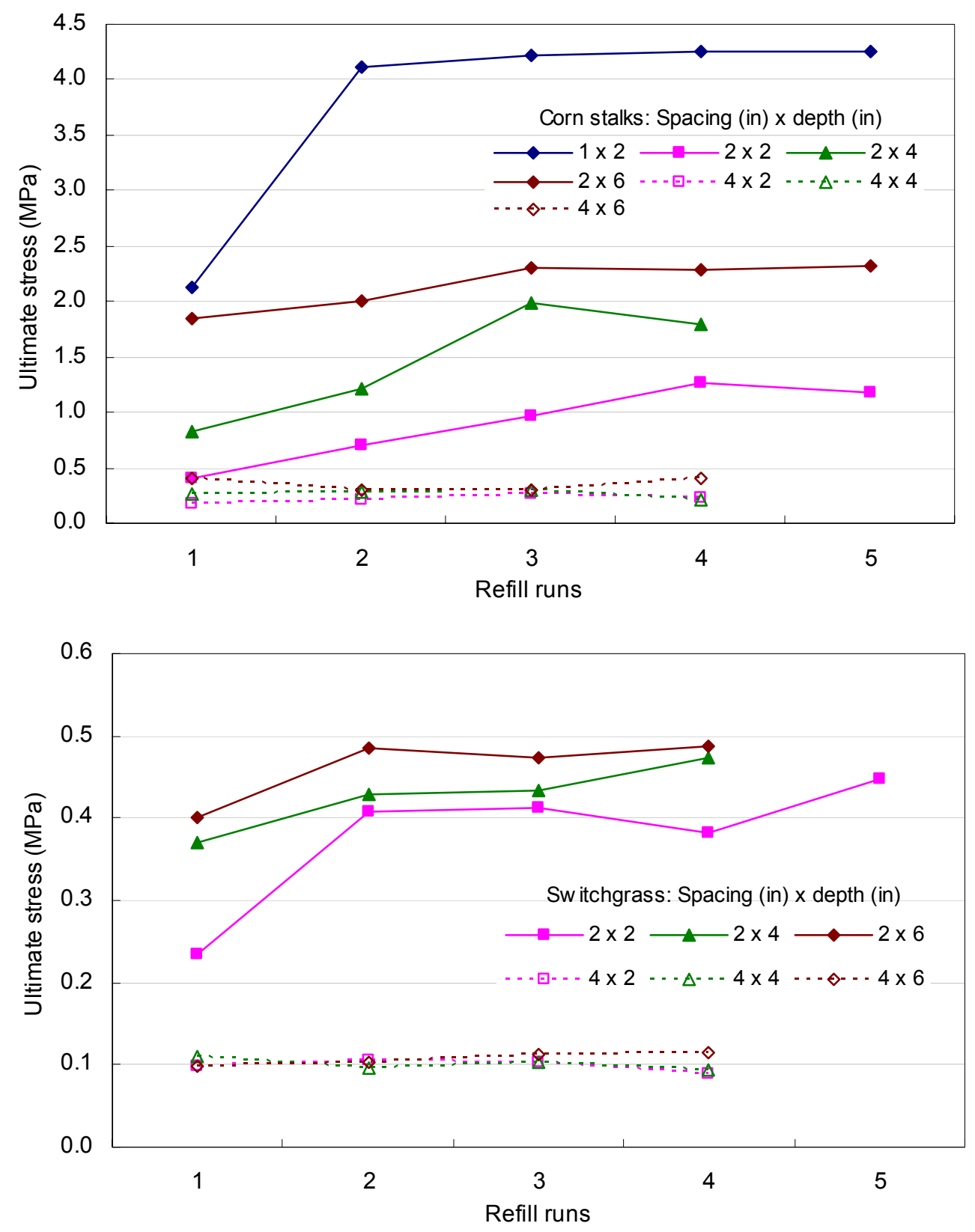

Figure 7. Ultimate cutting stress for corn stalks and switchgrass with different knife grid spacing and fill depths.

The variation of ultimate cutting stress reduced with increased spacing. It can be observed that the ultimate stress and energy stayed relatively constant in the subsequent refills after the initial filling. This meant that continuous operations with fillings were possible as ultimate stress remained fairly unaltered. A single experiment conducted with $25.4 \mathrm{~mm}$ knife grid spacing, demonstrated the high load requirement, even at $50.8 \mathrm{~mm}$ fill depth. The less variation from the $2^{\text {nd }}$ refill runs in this case of $25.4 \mathrm{~mm}$ grid spacing was actually due to reaching of the maximum load limit, rather than the maximum displacement limit as seen with all other grid spacing runs. Both corn stalks and switchgrass showed similar ultimate cutting stress variation with refill runs, though the magnitudes of ultimate cutting stress values were less for switchgrass. 


\section{Net Cutting Energy}

Figure 8 shows net cutting energy variation of corn stalks and switchgrass based on knife grid spacing and depth of filling with the number of refills. Corn stalks required almost four times the energy that of switchgrass. Net cutting energy requirement was reduced at larger grid spacing and was increased with increased fill depths. Net energy showed clear increase with increase in fill depth at any refill run.
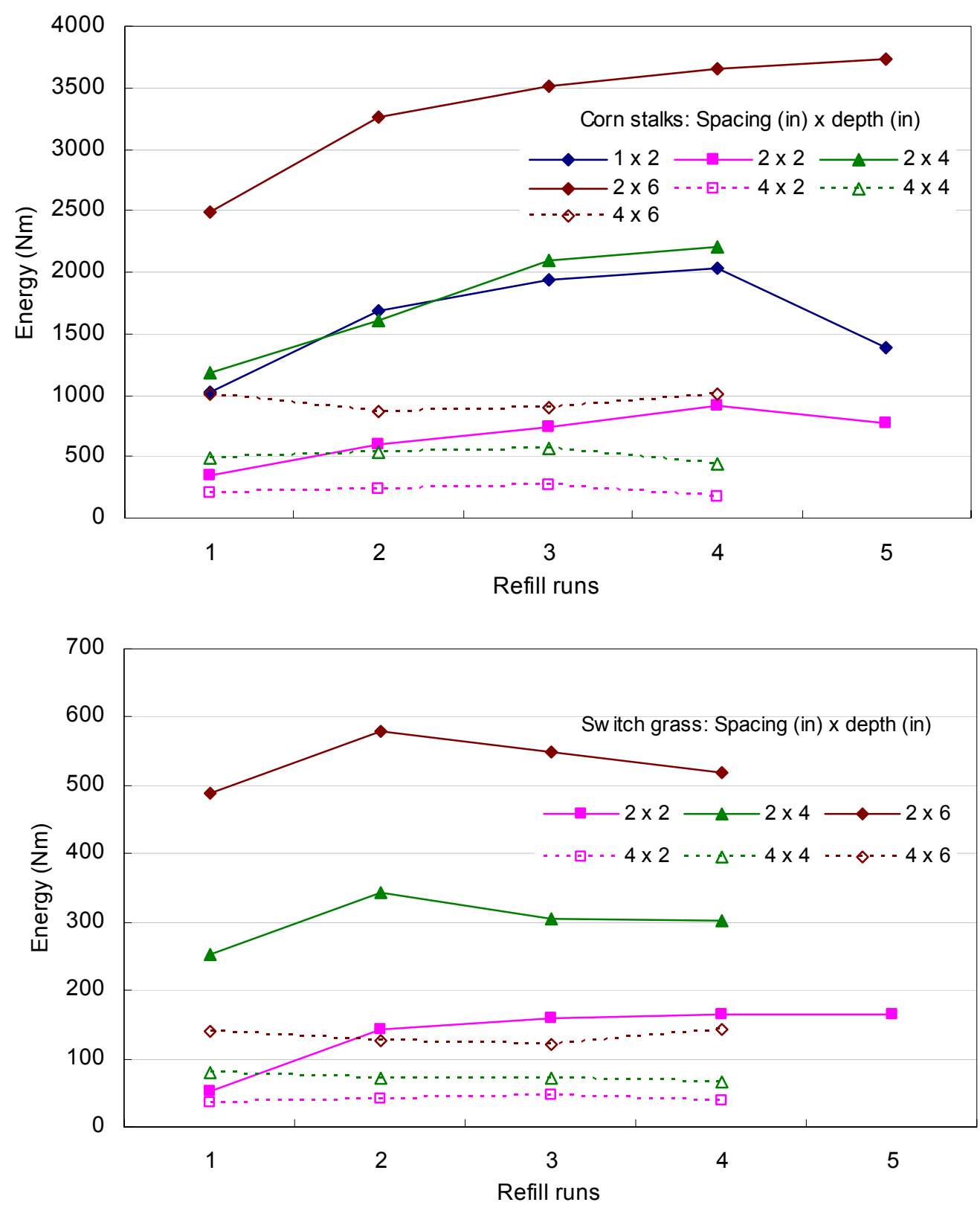

Figure 8. Net energy for corn stalks and switchgrass with different knife grid spacing and fill depths.

Depth of refill depicts the quantity of material handled, hence the net energy increased with the increased sample loading into the feed block. A sharp net energy increase from the initial filling to the $2^{\text {nd }}$ refill was observed, and the energy increase was gradual during the subsequent 
fillings or showed stabilization and even reduction in many situations. Flattening of the curve after the $3^{\text {rd }}$ or $4^{\text {th }}$ refills depicts the stable operation of the device, after the initial priming of biomass into the device.

In the case of corn stalks, it is interesting to observe that the energy of incomplete $25.4 \mathrm{~mm}$ grid spacing run with $50.8 \mathrm{~mm}$ fill depth was smaller than the runs with $50.8 \mathrm{~mm}$ grid spacing with $101.6 \mathrm{~mm}$ fill depth and above. Net energy variations of switchgrass with refill runs were flatter and more stabilized than that of corn stalks.

\section{Cutting Process Energy - Mass Basis}

Table 1 presents the cutting process energy required per ton based on the cumulative energy of all refill runs with input material handled and product produced bases. Since the product produced was always less than the original input, owing to some portion of the input was held compressed cut between the clearance of ram and knife edges, the energy required on product basis will be proportionally larger. On a continuous operation, after meeting the storage requirement inside the device, the input mass should be the same as the product mass; thus giving rise to a reduced energy requirement on input basis. Hence it is logical to use the input basis for all estimations. Energy requirement on the product basis was around $15 \%$ higher than that obtained from the input basis.

Table 1. Cutting process energy based on mass.

\begin{tabular}{|c|c|c|c|c|c|c|c|c|c|c|}
\hline \multirow[t]{2}{*}{ Material } & \multirow{2}{*}{$\begin{array}{r}\text { Spacing } \\
(\mathrm{mm}) \\
\end{array}$} & \multirow{2}{*}{$\begin{array}{r}\text { Fill } \\
\text { depth } \\
(\mathrm{mm})\end{array}$} & \multirow{2}{*}{$\begin{array}{r}\text { Input } \\
\text { (g) }\end{array}$} & \multirow{2}{*}{$\begin{array}{r}\text { Product } \\
\text { (g) }\end{array}$} & \multirow{2}{*}{$\begin{array}{r}\text { Cum. } \\
\text { energy } \\
(\mathrm{Nm})\end{array}$} & \multicolumn{2}{|c|}{$\begin{array}{c}\text { Cutting process } \\
\text { energy requirement } \\
(\mathrm{kWh} / \mathrm{t})\end{array}$} & \multirow[t]{2}{*}{$\begin{array}{c}\text { No of } \\
\text { blades }\end{array}$} & \multirow{2}{*}{$\begin{array}{l}\text { New } \\
\text { area* } \\
\left(\mathrm{m}^{2}\right)\end{array}$} & \multirow{2}{*}{$\begin{array}{r}\text { Specific } \\
\text { energy } \\
(\mathrm{kN} / \mathrm{m})\end{array}$} \\
\hline & & & & & & $\begin{array}{l}\text { Input } \\
\text { basis }\end{array}$ & $\begin{array}{c}\text { Product } \\
\text { basis }\end{array}$ & & & \\
\hline Corn & 50.8 & 50.8 & 708 & 571 & 3364.3 & 1.32 & 1.64 & 6 & 0.0495 & 67.90 \\
\hline \multirow[t]{5}{*}{ stalks } & 50.8 & 101.6 & 1213 & 1032.5 & 7082.9 & 1.62 & 1.91 & 6 & 0.0991 & 71.47 \\
\hline & 50.8 & 152.4 & 2182 & 1971.9 & 16644.7 & 2.12 & 2.34 & 6 & 0.1486 & 111.98 \\
\hline & 101.6 & 50.8 & 611 & 523 & 858.5 & 0.39 & 0.46 & 2 & 0.0165 & 51.98 \\
\hline & 101.6 & 101.6 & 1183 & 1103 & 2042.5 & 0.48 & 0.51 & 2 & 0.0330 & 61.83 \\
\hline & 101.6 & 152.4 & 1874 & 1758 & 3776 & 0.56 & 0.60 & 2 & 0.0495 & 76.21 \\
\hline Switch & 50.8 & 50.8 & 416.5 & 312.3 & 683.4 & 0.46 & 0.61 & 6 & 0.0310 & 22.07 \\
\hline \multirow[t]{5}{*}{ grass } & 50.8 & 101.6 & 677 & 586.4 & 1202.3 & 0.49 & 0.57 & 6 & 0.0619 & 19.41 \\
\hline & 50.8 & 152.4 & 1125 & 1033.6 & 2137.9 & 0.53 & 0.57 & 6 & 0.0929 & 23.01 \\
\hline & 101.6 & 50.8 & 374 & 308 & 161.1 & 0.12 & 0.15 & 2 & 0.0103 & 15.61 \\
\hline & 101.6 & 101.6 & 577 & 522 & 285.7 & 0.14 & 0.15 & 2 & 0.0206 & 13.84 \\
\hline & 101.6 & 152.4 & 918 & 853 & 531.1 & 0.16 & 0.17 & 2 & 0.0310 & 17.15 \\
\hline
\end{tabular}

* New surface area generated $=$ Number of blades $\times$ fill depth $\times$ fixed cut length $(203.2 \mathrm{~mm}) \times$ packing density

On average, based on input the process energy required were $1.69 \pm 0.81$ and $0.48 \pm 0.08 \mathrm{kWh} / \mathrm{t}$ for corn stalks and $0.49 \pm 0.04$ and $0.14 \pm 0.02 \mathrm{kWh} / \mathrm{t}$ for switchgrass for a product size of 50 and $101 \mathrm{~mm}$, respectively. Corn stalks required 3.3 to 3.4 times higher cutting energy than the switchgrass among all settings. It should be noted that the energy values reported herein were the total of all the refill runs of a particular spacing and depth settings. Hence, energy estimates will deviate on a continuous operation, where each run produces the product, but the normalization based on unit weight will addresses a part of the deviation.

Published results indicate $14.9 \mathrm{kWh} / \mathrm{t}$ for switchgrass chopping from bales to 25 to $100 \mathrm{~mm}$ size (Jannasch, et al. 2005), $23.5 \mathrm{kWh} / \mathrm{t}$ using hammer mill producing a product size of $3.2 \mathrm{~mm}$ (Mani, et al. 2002). Machine type, mode of cutting, and reduced product size were the reasons 
for these increased reported values. The present results were smaller than the published values.

\section{Specific Cutting Energy - New Surface Area Basis}

Theoretically evaluated new surface areas generated by the linear knife grid and the specific energy based on new surface area generated were also presented in Table 1. Corn stover equivalent diameter varied from 5 to $26 \mathrm{~mm}$. From these values, a geometric mean dimension of $\sim 18 \mathrm{~mm}$ was selected as the representative diameter of corn stalks. For switchgrass stems, considered geometrically as a hollow cylinder, an approximate representative dimensions of outer diameter of $\sim 5 \mathrm{~mm}$ and wall thickness of $\sim 1 \mathrm{~mm}$ was chosen based on random measurements. Packing density values calculated from these dimensions are presented in Table 2.

Table 2. Packing density of corn stalks and switchgrass for new surface area generation.

\begin{tabular}{|c|c|c|c|c|c|c|c|c|}
\hline Material & Depth & Length & $\begin{array}{l}\text { No of } \\
\text { rows }\end{array}$ & $\begin{array}{l}\text { No of } \\
\text { columns }\end{array}$ & $\begin{array}{l}\text { Total } \\
\text { number } \\
\text { of } \\
\text { particles }\end{array}$ & $\begin{array}{l}\text { Total area } \\
\text { of } \\
\text { particles } \\
\qquad\left(\mathrm{mm}^{2}\right)\end{array}$ & $\begin{array}{l}\text { Total } \\
\text { available } \\
\text { area } \\
\quad\left(\mathrm{mm}^{2}\right)\end{array}$ & $\begin{array}{l}\text { Packing } \\
\text { density }\end{array}$ \\
\hline \multirow[t]{3}{*}{ Corn stalks } & 50.8 & 203.2 & 3 & 11 & 33 & 8397.48 & 10322.56 & 0.814 \\
\hline & 101.6 & 203.2 & 6 & 11 & 66 & 16794.95 & 20645.12 & 0.814 \\
\hline & 152.4 & 203.2 & 8 & 11 & 88 & 22393.27 & 30967.68 & 0.723 \\
\hline \multirow[t]{3}{*}{ Switchgrass } & 50.8 & 203.2 & 10 & 41 & 410 & 5152.21 & 10322.56 & 0.499 \\
\hline & 101.6 & 203.2 & 20 & 41 & 820 & 10304.42 & 20645.12 & 0.499 \\
\hline & 152.4 & 203.2 & 30 & 41 & 1230 & 15456.64 & 30967.68 & 0.499 \\
\hline
\end{tabular}

From the calculated mean, a packing density value of 0.80 for corn stalks and 0.50 for switchgrass were selected and used in the results of new surface area generated by the knife grid operation (Table 1). These packing values may increase when actual test sample having a distribution of different diameters was used in the process. A theoretical maximum value of 0.9069 was possible in the densest packing scenario (Weisstein, 2006).

Mean values of specific energy based on new surface generated (Table 1) were estimated as $83.78 \pm 24.5$ and $63.34 \pm 12.2 \mathrm{kN} / \mathrm{m}$ for corn stalks and $21.50 \pm 1.9$ and $15.53 \pm 1.7 \mathrm{kN} / \mathrm{m}$ for switchgrass for a product size of 50 and $101 \mathrm{~mm}$, respectively. Corn stalk needed 3.9 to 4.1 times more cutting energy on new surface area basis than switchgrass among all settings. Womac et al. (2005) reported a value of 27.9 to $34.2 \mathrm{kN} / \mathrm{m}$ for dry corn stalks and 78.0 to 95.2 $\mathrm{kN} / \mathrm{m}$ for switchgrass based on cutting of single stem us Warner Bratzler shear testing procedure. They found that dry switchgrass cutting energy were $\sim 2.8$ times greater than dry corn stover, but a reversed trend was observed in this study. The variation may be due to the deviation in selection of dimensions, and the input material used in this work contained all components including leaves and not exclusive of stems switchgrass as considered by Womac et al. (2005).

\section{Example Scale-up of Cutting Process}

Using the specific energies obtained, the linear knife grid cutting process can be scaled up to any size of operation with suitable assumptions.

Example: Total energy requirement for a linear knife grid device having an overall working area of $1.22 \times 1.22 \mathrm{~m}$ with knife grid spacing of $0.305 \mathrm{~m}$ (1 foot) square arrangement cutting corn stalks bale of size $1.0 \times 1.22 \times 1.22 \mathrm{~m}$ is as follows: 


$$
\begin{aligned}
& \text { Assuming specific energy for corn } \quad=83.8 \mathrm{kN} / \mathrm{m} \\
& \text { Assuming packing density for corn } \quad=0.8 \\
& \text { Number of knives per column } \quad=(1.22 / 0.305)-1=3 \\
& \text { Number of knives per row } \quad=(1.22 / 0.305)-1=3 \\
& \text { Total number of knives } \quad=\text { Column knifes }+ \text { row knives }=3+3=6 \\
& \text { Total area generated by knife grid= Feed depth } \times \text { knife length } \times \text { packing density } \times \text { number } \\
& \text { of knives } \\
& =1 \times 1.22 \times 0.8 \times 6=5.856 \mathrm{~m}^{2} \\
& \text { Energy requirement for the knife grid }=\text { Total area generated } \times \text { specific energy } \\
& =8.856 \times 83.8=490.7 \mathrm{kNm}=0.136 \mathrm{kWh}=0.18 \mathrm{hph}
\end{aligned}
$$

Scaling up is highly feasible for large product sizes and also for the sizes tested, because the determined specific energy values are well below the reported values for similar crops. The reduced power requirement makes the linear knife grid based size reduction devices well suited for preprocessing of biomass.

\section{Conclusions}

1. Corn stalks and switchgrass underwent large amount of deformation and compression before actual cutting under knife grid.

2. Embedding of cut product, especially at smaller knife grid spacing, offered additional resistance because of difference in areas above and below the knife grid.

3. Ultimate cutting stress and net energy requirements increased with increasing fill depth and decreasing knife grid spacing. Stabilization of ultimate cutting stress and net energy was observed after first cutting run for both the crops.

4. Corn stalks required 3.3 to 3.4 and 3.9 to 4.1 times higher specific energy of cutting than switchgrass on mass and new surface area generated energy basis, respectively. The respective limits ranged from 0.39 to $2.12 \mathrm{kWh} / \mathrm{t}$ and 52.0 to $112.0 \mathrm{kN} / \mathrm{m}$ for corn stalks and 0.12 to $0.53 \mathrm{kWh} / \mathrm{t}$ and 13.8 to $23.0 \mathrm{kN} / \mathrm{m}$ for switchgrass.

5. Cutting energy values determined for corn stalks and switchgrass under linear knife gird device were either smaller or agreed well with the reported values.

6. Scaling up of the linear knife grid device for larger product sizes greater than $100 \mathrm{~mm}$ can be readily adopted.

\section{Acknowledgements}

Assistance extended by Dr. David Harper, Assistant Professor and Mr. Chris Helton, Research Coordinator of Forest Products Center, The University of Tennessee, Knoxville is highly appreciated.

\section{References}

ASAE Standards. 2003. S358.2: Moisture measurement - forages. St. Joseph, Mich.: ASABE. Brennan, J. G., J. R. Butters, N. D. Cowell, and A. E. V. Lilley. 1990. Food Engineering Operations. 3rd ed. London: Elesvier Applied Science.

Chancellor, W. J. 1958. Energy requirement for cutting forage. Agric. Eng. 39(10): 633-636. 
Chen, Y., J. L. Gratton, and J. Liu. 2004. Power requirements of hemp cutting and conditioning. Biosystems Eng. 87 (4): 417-424.

Dowgiallo, A. 2005. Cutting force of fibrous materials. J. Food Eng. 66(1)57-61.

El Hag, H. E., O. R. Kunze, and L. H. Wilkes. 1971. Influence of moisture, dry-matter density and rate of loading on ultimate strength of cotton stalks. Trans. ASAE 13(3): 713-716.

Igathinathane, C., A. R. Womac, S. Sokhansanj, and L. O. Pordesimo. 2006. Mass and moisture distribution in aboveground components of standing corn plants. Trans. ASAE 49(1): 97-106.

Jannasch, R., Y. Quan, and R. Samson. 2005. A process and energy analysis of palletizing switchgrass. Resource Efficient Agricultural Production (REAP-Canada). www.reapcanada.com. Accessed on Nov. 2005.

Mani, S., L.G. Tabil, and S. Sokhansanj. 2002. Grinding performance and physical properties of selected biomass. ASAE Paper No. 026175. St. Joseph, Mich.: ASABE.

Mesquita, C. M., and M. A. Hanna. 1995. Physical and mechanical properties of soybean crops. Trans. ASAE 38(6): 1655-1658.

O'Dogherty, M. J. 1982. A review of research on forage chopping. J. Agric. Eng. Res. 27(4): 267-289.

Persson, S. 1987. Mechanics of Cutting Plant Material. ASAE, St Joseph, MI, USA

Prasad, J., and C. P. Gupta. 1975. Mechanical properties of maize stalk as related to harvesting. J. Agric. Eng. Res. 20(2): 79-87.

Prince, R. P., J. W. Bartok Jr., and D. W. Bradway. 1969. Shear stress and modulus of elasticity of selected forages. Trans. ASAE 12(1): 426-429.

Womac, A. R., M. Yu, C. Igathinathane, P. Ye, D. Hayes, S. Narayan, S. Sokhansanj, and L. Wright. 2005. Shearing characteristics of biomass for size reduction. ASAE Paper No. 056058. St. Joseph, Mich.: ASABE.

Weisstein, E. W. 2006. Circle packing. In MathWorld. Champaign,III.: Wolfram Research, Inc. Available at: http://mathworld.wolfram.com/CirclePacking.html. Accessed May 2006.

Yu, M., Womac, A. R., and Pordesimo, L. O. 2003. Review of biomass size reduction technology. ASAE Paper No. 036077. St. Joseph, Mich.: ASABE. 